\title{
The Accumulation of Heparan Sulfate S-Domains in Kidney Transthyretin Deposits Accelerates Fibril Formation and Promotes Cytotoxicity
}

Hirokazu Kameyama, ${ }^{*}$ Kenji Uchimura, ${ }^{\dagger \ddagger}$ Taro Yamashita, ${ }^{\S}$ Kaori Kuwabara, ${ }^{*}$ Mineyuki Mizuguchi, ${ }^{\circledR}$ Shang-Cheng Hung, Keiichiro Okuhira, ${ }^{*}$ Tomohiro Masuda, ${ }^{* *}$ Tomoki Kosugi, ${ }^{* *}$ Takashi Ohgita, ${ }^{\dagger \dagger}$ Hiroyuki Saito, ${ }^{\dagger \dagger}$ Yukio Ando, ${ }^{\S}$ and Kazuchika Nishitsuji ${ }^{\ddagger £ \S}$

From the Departments of Molecular Physical Pharmaceutics* and Pathology and Laboratory Medicine, ${ }^{\S \S}$ Institute of Biomedical Sciences, Tokushima University Graduate School, Tokushima, Japan; the Departments of Biochemistry ${ }^{\dagger}$ and Nephrology, ** Nagoya University Graduate School of Medicine, Nagoya, Japan; the Unité de Glycobiologie Structurale et Fonctionnelle, ${ }^{\ddagger}$ UMR 8576 CNRS, Université de Lille 1, Villeneuve d'Ascq, France; the Department of Neurology, ${ }^{\S}$ Graduate School of Medical Sciences, Kumamoto University, Kumamoto, Japan; the Faculty of Pharmaceutical Sciences, ${ }^{\circledR}$ University of Toyama, Toyama, Japan; the Genomics Research Center, ${ }^{\|}$Academia Sinica, Taipei, Taiwan; the Department of Biophysical Chemistry, ${ }^{\dagger \dagger}$ Kyoto Pharmaceutical University, Kyoto, Japan; and the Department of Biochemistry, ${ }^{\ddagger \ddagger}$ Wakayama Medical University, Wakayama, Japan

Accepted for publication September 26, 2018.

Address correspondence to Kazuchika Nishitsuji, Ph.D., Department of Biochemistry, Wakayama Medical University, 811-1 Kimiidera, Wakayama 641-8509, Japan. E-mail: nishit@wakayama-med.ac.jp.

\begin{abstract}
The highly sulfated domains of heparan sulfate (HS), alias HS S-domains, are made up of repeated trisulfated disaccharide units [iduronic acid (2S)-glucosamine (NS, 6S)] and are selectively remodeled by extracellular endoglucosamine 6 -sulfatases (Sulfs). Although HS S-domains are critical for signal transduction of several growth factors, their roles in amyloidoses are not yet fully understood. Herein, we found HS S-domains in the kidney of a patient with transthyretin amyloidosis. In in vitro assays with cells stably expressing human Sulfs, heparin, a structural analog of HS S-domains, promoted aggregation of transthyretin in an HS S-domain-dependent manner. Interactions of cells with transthyretin fibrils and cytotoxicity of these fibrils also depended on HS S-domains at the cell surface. Furthermore, glypican-5, encoded by the susceptibility gene for nephrotic syndrome GPC5, was found to be accumulated in the transthyretin amyloidosis kidney. Our study, thus, provides a novel insight into the pathologic roles of HS S-domains in amyloidoses, and we propose that enzymatic remodeling of HS chains by Sulfs may offer an effective approach to inhibiting formation and cytotoxicity of amyloid fibrils. (Am J Pathol 2019, 189: 308-319; https://doi.org/10.1016/j.ajpath.2018.09.015)
\end{abstract}

Highly sulfated domains of heparan sulfate (HS), alias HS S-domains, consist of consecutive clusters of a trisulfated disaccharide unit [iduronic acid (2S)-glucosamine (NS, 6S)]. ${ }^{1}$ These HS S-domains are a major determinant of specific interactions between $\mathrm{HS}$ and its protein ligands, including growth factors, chemokines, and morphogens, and thus they regulate HS functions in diverse biological processes. $^{2,3}$ In addition to being involved in biological processes, HS is associated with various amyloid deposits, including those in transthyretin amyloidosis (ATTR amyloidosis), ${ }^{4}$ Alzheimer disease (AD), ${ }^{5-7}$ light-chain amyloidosis, ${ }^{8}$ and amyloid A (AA) amyloidosis, ${ }^{9}$ which suggests that HS may affect amyloid deposition and amyloidosis pathology. Indeed, HS and heparin, whose major components are HS S-domains, reportedly promoted fibrillogenesis of various amyloidogenic proteins, such as transthyretin (TTR) in ATTR amyloidosis, ${ }^{4,10}$ amyloid $\beta$ $(\mathrm{A} \beta)$ in $\mathrm{AD},{ }^{11-13}$ cellular prion, Ig light chain in light-chain amyloidosis, $^{14}$ and serum AA in AA amyloidosis. ${ }^{15-17}$ Also, HS at the cell surface mediated interactions of cells with and cytotoxicity of amyloid fibrils or protein aggregates, including those of $\tau$ protein and $\alpha$-synuclein, ${ }^{18} \mathrm{~A} \beta,{ }^{19}$

\footnotetext{
Supported in part by the Japan Society for the Promotion of Science grants-in-aid for young scientists B-15K19488 (K.N.) and B-17K16123 (K.N.) and the MEXT/JSPS grants-in-aid JP15K08265 (K.U.) and JP16KK0202 (K.U.).

Disclosures: None declared.
} 
and mutant apolipoprotein A-I (apoA-I). ${ }^{20}$ We and others previously reported that HS S-domains accumulated with tissue amyloid in brains of patients with $\mathrm{AD}$ and brains of mouse AD models. ${ }^{21,22}$ These lines of evidence suggest that HS S-domains may be key elements in amyloidoses, ${ }^{23}$ a suggestion that is also supported by our previous study showing that HS S-domains mediated interactions of cells with fibrils of the G26R mutant apoA-I and cytotoxicity of these fibrils. ${ }^{20}$ However, involvement of HS S-domains in other amyloidoses, such as ATTR amyloidosis, which is the most common form of hereditary amyloidosis, has not been addressed. $^{24}$

Amyloidoses are caused by abnormal depositions of amyloid fibrils. Although the sequences of amyloidogenic proteins vary, amyloid fibrils share a common structure-the cross- $\beta$ structure. ${ }^{25}$ Currently, $>30$ amyloidogenic proteins have been identified in humans. ${ }^{26}$ TTR in plasma is present as a homotetramer composed of four $14-\mathrm{kDa}$ monomers. ${ }^{27}$ TTR is predominantly synthesized by the liver and the choroid plexus and transports retinol and thyroxine. ${ }^{28}$ In addition to having physiological functions, TTR is an amyloidogenic component of amyloid fibrils in several types of amyloidoses, including familial ATTR amyloidosis ${ }^{29}$ and senile systemic amyloidosis. ${ }^{30}$ Symptoms of ATTR amyloidosis, which depend on the site of deposition, include peripheral neuropathy, gastrointestinal tract impairment, cardiomyopathy, nephropathy, and ocular manifestations. ${ }^{31}$ Autosomal dominant ATTR amyloidosis caused by variant forms of TTR is the most common form of hereditary amyloidosis. Several endemic foci have been found in Japan, Sweden, and Portugal. ${ }^{31}$ More than 100 amyloidogenic mutations in TTR have been reported, ${ }^{27}$ although wild-type (WT) TTR also forms amyloid fibrils, which suggests that the mutations are not the sole determinant of amyloid formation. ${ }^{32}$ Indeed, TTR fibrillization is reportedly initiated by dissociation of tetramers into monomers that can misfold and aggregate into fibrils. ${ }^{33}$ In addition, amyloid fibrils do not deposit alone but rather deposit together with nonamyloid protein components ${ }^{34}$ and nonprotein components. ${ }^{35}$ These data indicate the existence of a cofactor for formation and deposition of aggregates formed by WT TTR and variant TTRs. ATTR amyloidosis is characterized by deposition of TTR fibrils in various tissues, including the kidney, which is the most frequent site of deposition. ${ }^{36}$ TTR deposition in the kidney leads to renal injury associated with various clinical manifestations, ranging from proteinuria to endstage kidney failure. ${ }^{37}$ As an intriguing finding, HS is the major component of glomerular basement membranes. ${ }^{38}$

Herein, to identify potential cofactors for TTR deposition in tissues, we studied the involvement HS S-domains in ATTR amyloidosis. HS S-domains were detected in tissues obtained from patients with ATTR amyloidosis by using the RB4CD12 antibody, which specifically recognizes HS S-domains. ${ }^{39}$ Previously, Chinese hamster ovary (CHO) cells that stably expressed the extracellular endoglucosamine 6-sulfatase human sulfatase 2 (HSulf-2) were established. ${ }^{40}$ Sulf- 2 enzymatically remodels extracellular HS by removing C-6 sulfate groups in HS S-domains and thereby regulates interactions between the HS S-domains and their protein ligands. ${ }^{41}$ By using $\mathrm{CHO}$ cells that stably expressed the extracellular endoglucosamine 6-sulfatase HSulf-2, it was shown that formation of fibrils and interactions of cells with fibrils generated by various TTR fragments depended on HS S-domains. Moreover, glypican-5 (GPC5) was detected in glomeruli obtained from patients with ATTR amyloidosis. The GPC5 gene is a recently identified new susceptibility gene for acquired nephrotic syndrome that may confer susceptibility to that syndrome by hyperactivating fibroblast growth factor 2 (FGF2) signaling. ${ }^{42}$ Our results support the importance of HS S-domains and their enzymatic remodeling by Sulf- 2 in the pathogenesis of ATTR amyloidosis and development of therapeutic strategies, ${ }^{43}$ and they point to GPC5 as a new therapeutic target to reduce renal injury in ATTR amyloidosis.

\section{Materials and Methods}

\section{Materials}

After receiving approval from the Kumamoto University Research Ethical Committee, informed consent was obtained from all study subjects. Table 1 provides details about study subjects and postmortem tissues. Formalin-fixed, paraffin-embedded sections of normal kidney were obtained from BioChain Institute Inc. (Newark, CA), according to ethical standards and procedures approved by the institutional review board. WT TTR 81 to 127 fragments were expressed by Escherichia coli and purified. WT TTR, V30M mutant TTR 12 to 35 fragments, and the C-terminal fragment with amino acid residues 105 to 123 were purchased from Eurofins Genomics (Tokyo, Japan). CHO cells that were stably transfected with HSulf-2-encoding cDNA were established as previously described. ${ }^{40}$ A conditionally immortalized human podocyte cell line was established by Saleem et al. ${ }^{44}$ Mouse mesangial cells (SV40 MES 13, number CRL-1927) were purchased from ATCC (Manassas, VA). Porcine intestinal mucosa heparin was coupled to bovine serum albumin (BSA) at its reducing end on the basis of the procedure described by Najjam et al. $^{45}$ The

Table 1 Basic Characteristics of Human Subjects and Postmortem Tissues

\begin{tabular}{lcc}
\hline Characteristic & $\begin{array}{c}\text { Control } \\
(n=2)\end{array}$ & $\begin{array}{c}\text { ATTR patients } \\
(n=8)\end{array}$ \\
\hline Female/male ratio & $2: 0$ & $5: 3$ \\
Age, years & 78 & $44 \pm 8.6$ \\
Liver transplantation & 0 & 3 \\
Mutation & NA & V30M \\
Amyloid deposition in & 0 & 5 \\
$\quad$ the glomeruli & & \\
$\begin{array}{l}\text { Accumulation of HS S-domains } \\
\text { in amyloid deposits }\end{array}$ & 0 & 4 \\
\hline
\end{tabular}

Data are expressed as mean or means $\pm S D$, unless indicated otherwise. NA, not applicable. 
conjugates were referred to as heparin-BSA. Thioflavin T (ThT) was purchased from Sigma (St. Louis, MO). An anti- $\beta$-actin antibody was purchased from Sigma, and a rabbit monoclonal anti-GPC5 antibody was purchased from Abcam (Cambridge, MA). RB4CD12 anti-S-domain antibody $^{22}$ was kindly provided by Dr. Toin H. van Kuppevelt (Nijmegen Center for Molecular Life Sciences, Radboud University Nijmegen Medical Center, Nijmegen, the Netherlands). Mouse IgG and IgM isotype controls were obtained from Abcam, and a rabbit IgG isotype control was from Thermo Fisher Scientific (Waltham, MA).

\section{Monitoring Fibril Formation}

Fibril formation was monitored by means of $\mathrm{ThT}^{46}$ as previously described, ${ }^{47}$ except that we used Black 96-Well Immuno Plates (Thermo Fisher Scientific) that were coated with BSA (control) or heparin-BSA conjugates. To eliminate S-domains from heparin, each well of the heparinBSA-coated plate was incubated with the culture medium of $\mathrm{CHO}$ cells that stably expressed HSulf- $2 .^{48}$ To monitor formation of fibrils by TTR fragments, TTR fragments (30 $\mu \mathrm{mol} / \mathrm{L}$ ) in phosphate-buffered saline (PBS; $\mathrm{pH} 7.4$ ) were incubated in the presence of $10 \mu \mathrm{mol} / \mathrm{L} \mathrm{ThT}$ at $37^{\circ} \mathrm{C}$ with agitation on an orbital rotator. Fluorescence of ThT was recorded from 460 to $600 \mathrm{~nm}$ with an excitation wavelength of $445 \mathrm{~nm}$. The area under the curve was determined by using Prism 7 software (GraphPad Software, La Jolla, CA).

\section{Cell Culture}

WT CHO cells and their variants were cultured in a 1:1 mixture of Dulbecco's modified Eagle's medium and Ham's F-12 Nutrient Mixture (Sigma) supplemented with 10\% heat-inactivated fetal bovine serum (Lonza Group Ltd, Basel, Switzerland), $100 \mathrm{U} / \mathrm{mL}$ penicillin, and $100 \mu \mathrm{g} / \mathrm{mL}$ streptomycin (Sigma) at $37^{\circ} \mathrm{C}$ in $95 \%$ air and $5 \% \mathrm{CO}_{2}$. Immortalized human podocytes were maintained in RPMI 1640 medium (Thermo Fisher Scientific) containing 10\% fetal bovine serum, $1 \%$ Insulin-Transferrin-Selenium-A Supplement (Thermo Fisher Scientific), $100 \mathrm{U} / \mathrm{mL}$ penicillin, and $100 \mu \mathrm{g} / \mathrm{mL}$ streptomycin. Cells were grown at $33^{\circ} \mathrm{C}$ in $95 \%$ air and $5 \% \mathrm{CO}_{2}$ and were then differentiated at $37^{\circ} \mathrm{C}$ for 7 days. $^{44}$ SV40 MES 13 mouse mesangial cells were cultured in a 3:1 mixture of Dulbecco's modified Eagle's medium and Ham's F-12 Nutrient Mixture containing $14 \mathrm{mmol} / \mathrm{L}$ HEPES (Sigma), 5\% fetal bovine serum, $100 \mathrm{U} /$ $\mathrm{mL}$ penicillin, and $100 \mu \mathrm{g} / \mathrm{mL}$ streptomycin at $37^{\circ} \mathrm{C}$ in an atmosphere containing $5 \% \mathrm{CO}_{2}$.

\section{Analysis of HS S-Domains by Enzyme-Linked Immunosorbent Assay}

Heparin was immobilized by adding $100 \mathrm{ng} / \mathrm{mL}$ heparinBSA conjugates in PBS to wells (100 $\mu \mathrm{L} /$ well) of Black 96Well Immuno Plates. The plates were kept at $4{ }^{\circ} \mathrm{C}$ overnight.
The wells were washed three times with PBS containing $0.1 \%$ Tween-20 and were then blocked with 3\% BSA (Sigma) in PBS at room temperature for 2 hours, after which the wells were washed with PBS containing $0.1 \%$ Tween-20 and incubated with the primary antibody (RB4CD12, 1:750 in $0.1 \% \mathrm{BSA} / \mathrm{PBS}, 100 \mu \mathrm{L} /$ well) at room temperature for 1 hour. After being washed, the wells were incubated with $100 \mu \mathrm{L} /$ well of the secondary antibody, rabbit anti-vesicular stomatitis virus antibody conjugated with Cy5 (Sigma; $1 \mu \mathrm{g} / \mathrm{mL}$ in $0.1 \%$ BSA in PBS), at room temperature for 45 minutes. The fluorescence intensity of each well was analyzed by using an Infinite M200 microplate reader (Tecan Japan Co, Ltd, Kanagawa, Japan).

\section{Preparation of TTR Fibrils}

WT TTR, V30M mutant TTR 12 to 35 fragments, the Cterminal fragment with amino acid residues 105 to 123 , and WT TTR 81 to 127 fragments were solubilized in PBS to give a final concentration of $30 \mu \mathrm{mol} / \mathrm{L}$, and the solutions were incubated in a microcentrifugation tube in a rotating mixer for 7 days at $37^{\circ} \mathrm{C}$. Fibril formation was confirmed by using atomic force microscopy (AFM).

\section{AFM Analysis}

For AFM analysis, $10 \mu \mathrm{L}$ of each fibril solution $(30 \mu \mathrm{mol} / \mathrm{L})$ in $10 \mathrm{mmol} / \mathrm{L}$ PBS was diluted with $45 \mu \mathrm{L}$ of distilled water and spotted on freshly cleaved mica (Nilaco Corp., Tokyo, Japan). After the mica was washed with $20 \mu \mathrm{L}$ of distilled water, sample images were obtained under ambient conditions at room temperature via NanoScope IIIa Tapping Mode AFM (Veeco Instrument, Plainview, NY) and a single-crystal microcantilever OMCLAC160TS-R3 (Olympus, Tokyo, Japan) at a scan rate of $0.5 \mathrm{~Hz}$ in tapping mode.

\section{Analysis of Interactions of Cells with TTR Fibrils}

HS S-domain expression and its removal were successfully induced by plating $\mathrm{CHO}$ cells and their HSulf-2-expressing variants on coverslips coated with poly-L-lysine to prevent cells from detaching. ${ }^{20,40}$ Cells were plated onto the coated coverslips and cultured for 12 hours, after which they were incubated with CF488A dye-labeled TTR fibrils $(1 \mu \mathrm{mol} / \mathrm{L})$ at $37^{\circ} \mathrm{C}$ for 12 hours. TTR fibrils were labeled by using the CF488A Protein Labeling Kit (Biotium, Fremont, CA). Briefly, $100 \mu \mathrm{L}$ of $1 \mathrm{~mol} / \mathrm{L}$ sodium bicarbonate ( $\mathrm{pH}$ 8.3) was added to $1000 \mu \mathrm{L}$ of $30 \mu \mathrm{mol} / \mathrm{L}$ TTR fibrils in PBS solution. The CF488A dye was dissolved in $25 \mu \mathrm{L}$ of dimethyl sulfoxide, and the dye solution was added to the TTR fibril solution. After labeled TTR fibrils were incubated at room temperature in the dark for 1 hour, the fibrils were purified by using ultrafiltration vials with a 3-kDa cutoff (Millipore, Billerica, MA). The cells were fixed with $4 \%$ paraformaldehyde for 20 minutes at room temperature. The cells were washed three times with PBS and were mounted with 
Vectashield Mounting Medium with DAPI (Vector Laboratories, Burlingame, CA). The specimens were examined with an LSM710 confocal microscope. For quantification of TTR fibril-positive cells, 5 to 10 fields were randomly selected and the percentages of TTR fibril-positive cells was calculated from the total number of cells and number of amyloid-positive cells. The mean ratios of amyloid-positive cells/total cells were obtained.

\section{Cytotoxicity Assay}

Cytotoxicity was determined by measuring mitochondrial membrane potential with the mitochondrial membrane potential-sensitive fluorophore tetramethylrhodamine, ethyl ester (MitoPT assay kit; ImmunoChemistry Technologies, Bloomington, MN). Briefly, CHO cells and their variants were plated on poly-L-lysine-coated coverslips, cultured for 12 hours, and treated with TTR fibrils $(1 \mu \mathrm{mol} / \mathrm{L})$ at $37^{\circ} \mathrm{C}$ for 12 hours. After the cells were washed with PBS twice, they were spiked with $10 \mathrm{nmol} / \mathrm{L}$ tetramethylrhodamine, ethyl ester, at $37^{\circ} \mathrm{C}$ for 20 minutes in the dark. Tetramethylrhodamine, ethyl ester, fluorescence was detected by using an LSM710 confocal microscope (Carl Zeiss MicroImaging GmbH, Jena, Germany) with an excitation wavelength of $555 \mathrm{~nm}$. Mean fluorescence intensities were determined using ImageJ software version 1.50i (NIH, Bethesda, MD; http://imagej.nih.gov/ij).

\section{Immunohistochemistry}

Paraffin-embedded blocks of human tissue were cut into sections ( $3 \mu \mathrm{m}$ thick) and stained with alkaline Congo red after deparaffinization and rehydration. Stained specimens were examined under polarized light. ${ }^{49}$ After deparaffinization and rehydration of the sections, antigens were heat retrieved by boiling the sections in a pressure cooker in citrate buffer $(10 \mathrm{mmol} / \mathrm{L}$ sodium citrate and $0.05 \%$ Tween $20, \mathrm{pH} \mathrm{6.0)}$ for 20 minutes, after which sections were blocked in Animal-Free Blocker (Vector Laboratories) for 1 hour at room temperature. Sections were then incubated overnight at $4^{\circ} \mathrm{C}$ with primary antibodies: an anti-TTR antibody, 1:200 (Dako, Glostrup, Denmark); an anti-FGF2 antibody, 1:200 (Novus Biologicals, Littleton, CO); an anti-GPC5 antibody, 1:200 (Bioss Antibodies, Woburn, MA); the RB4CD12 antibody; the 10E4 anti-HS antibody, 1:50 (United States Biological, Salem, MA); or isotype controls in Animal-Free Blocker. After the samples were washed in PBS, primary antibodies were detected with the secondary antibody Alexa 488-conjugated polyclonal goat anti-rabbit IgG, Alexa 568-conjugated polyclonal goat anti-rabbit IgG, Alexa 568-conjugated polyclonal goat anti-mouse IgG, Alexa 488-conjugated polyclonal goat anti-mouse $\operatorname{IgM}(5 \mu \mathrm{g} / \mathrm{mL}$; Thermo Fisher Scientific), or Cy3-conjugated monoclonal anti-vesicular stomatitis virus $\mathrm{G}$ glycoprotein ( $4 \mu \mathrm{g} / \mathrm{mL}$; Sigma). Sections were mounted with Vectashield mounting medium and examined with an LSM710 confocal microscope.
Analysis of GPC5 Expression by Means of Western Blot Analysis

MES 13 cells or differentiated human podocytes were treated with fibrils of WT TTR 81 to 127 fragments $(1 \mu \mathrm{mol} / \mathrm{L})$ at $37^{\circ} \mathrm{C}$ for 12 hours. After incubation, cells were washed with PBS three times and were lysed by sonication in RIPA buffer [1\% Nonidet P-40, 0.5\% sodium deoxycholate, 0.1\% SDS, $150 \mathrm{mmol} / \mathrm{L} \mathrm{NaCl}, 50 \mathrm{mmol} / \mathrm{L}$ Tris- $\mathrm{HCl}(\mathrm{pH} 8.0)$, and 1 $\mathrm{mmol} / \mathrm{L}$ EDTA] containing a protease inhibitor cocktail (Roche Diagnostics, Basel, Switzerland). Cell lysates were subjected to SDS-PAGE with $4 \%$ to $20 \%$ gradient gels (Wako Pure Chemicals, Osaka, Japan) and were transferred to polyvinylidene difluoride membranes (Millipore). GPC5 was probed with an anti-GPC5 antibody (Abcam), followed by the secondary antibody (a horseradish peroxidase-labeled anti-rabbit antibody; Cell Signaling Technology, Beverly, MA) and the chemiluminescent substrate ImmunoStar LD (Wako Pure Chemicals). Signals were detected by using a Fujifilm LAS-3000 Imager (Fujifilm, Tokyo, Japan). The protein contents were normalized to the expression level of $\beta$ actin protein. To determine protein band densities, image files were analyzed with ImageJ software version 1.50i .

\section{Immunoprecipitation}

Cells were incubated with TTR fibrils $(1 \mu \mathrm{mol} / \mathrm{L})$ at $37^{\circ} \mathrm{C}$ for 12 hours, and cell lysates were prepared as described above. GPC5 in cell lysates was immunoprecipitated by using an anti-GPC5 antibody (Abcam) that was conjugated with Dynabeads Protein G (Thermo Fisher Scientific). The precipitates obtained were washed three times with PBS and heat treated at $70^{\circ} \mathrm{C}$ for 10 minutes in SDS-PAGE sample buffer. HS S-domains in the supernatants were detected by means of SDS-PAGE with $4 \%$ to $20 \%$ gradient gels, followed by immunoblotting with the RB4CD12 antibody and a horseradish peroxidase-conjugated mouse anti-vesicular stomatitis virus $\mathrm{G}$ glycoprotein antibody (Sigma). The signals were visualized and analyzed as described in the above section.

\section{Statistical Analysis}

Data were analyzed by means of the unpaired $t$-test. Results were considered significant when $P<0.05$.

\section{Results}

HS S-Domains and TTR Colocalized in the Kidney of an ATTR Amyloidosis Patient

Under polarized light, Congo red staining of sections of the kidney from a patient with ATTR amyloidosis demonstrated apple-green birefringence, which indicated deposition of amyloid fibrils in this specimen (Figure 1A). Immunostaining with an anti-TTR antibody confirmed deposition of TTR fibrils in glomeruli obtained from this patient; a control 
A

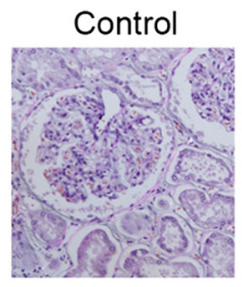

ATTR (V30M)

amyloidosis

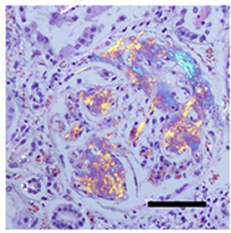

C
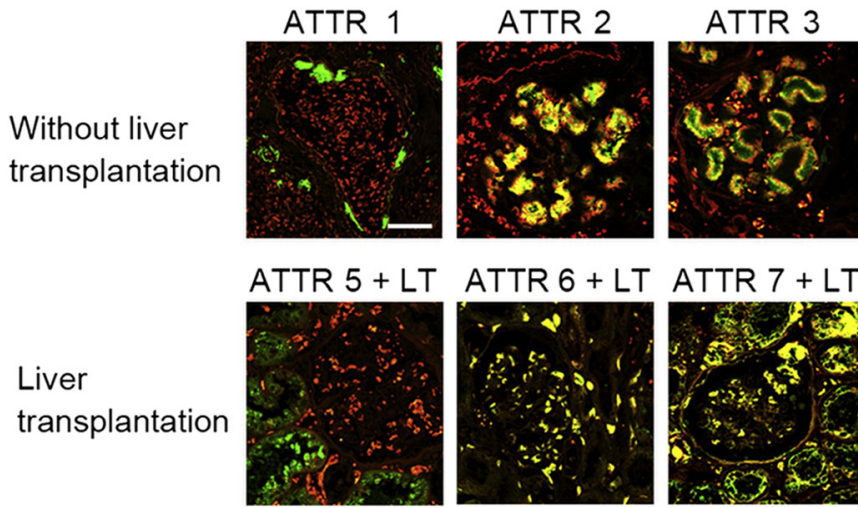

B

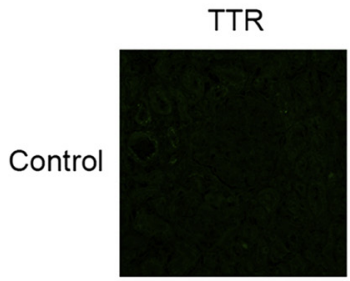

ATTR

(V30M) amyloidosis

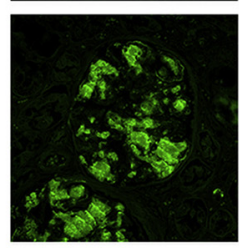

HS S-domain (RB4CD12)
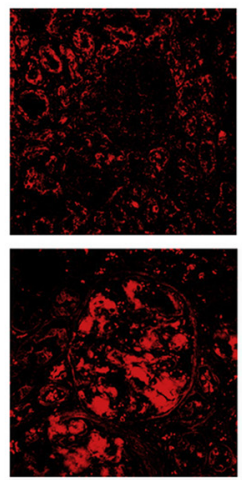

Merge

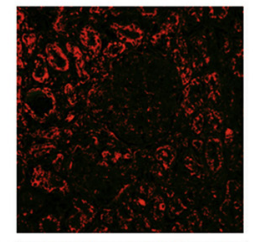

High maginification
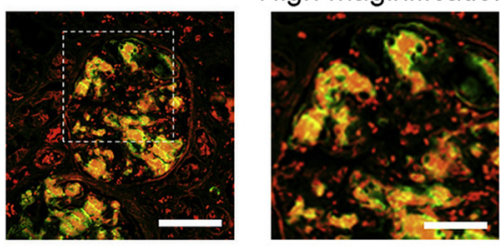

Figure 1 TTR and HS S-domains colocalize in the kidney of a 38-year-old patient with ATTR amyloidosis (V30M mutation). A: Renal sections were stained with Congo red and confirm the presence of amyloid depositions under polarized light. B: Additional sections were stained with RB4CD12 antibody and anti-TTR antibody. The merged image indicates that RB4CD12 staining colocalizes with TTR deposits in the glomeruli. Postmortem kidney sections prepared from subjects without amyloidosis were also used (Control). Boxed area is shown at higher magnification below. The highmagnification image demonstrates segmentally variable deposition involving the mesangium and capillary wall. C: Renal sections from patients with ATTR amyloidosis who underwent liver transplantation (LT; ATTR number 5 through $8+\mathrm{LT}$; bottom row) or did not undergo liver transplantation (ATTR number 1 through 4; top row) were stained with anti-TTR antibody (green) and RB4CD12 antibody (red). Scale bars: $50 \mu \mathrm{m}$ (A, B, main images, and $\mathbf{C}) ; 25 \mu \mathrm{m}$ (B, high-magnification).

section had no such deposition (Figure 1A). Expression of RB4CD12 epitopes was analyzed in sections from the same patient. Localized RB4CD12 epitopes (ie, highly sulfated domains of HS) were observed in glomeruli of this patient (Figure 1B). RB4CD12 signals completely overlapped with TTR signals (Figure 1B). The high-magnification image shows segmentally variable deposition involving the mesangium and capillary wall (Figure 1B). Among patients tested, five of the eight patients had amyloid deposits in the glomeruli, and four of the eight patients were positive for RB4CD12 staining (Table 1). Three of the five patients who did not receive liver transplantation were positive for both TTR deposits and HS S-domains, and one patient had TTR deposits but was HS S-domain negative (Figure 1C). The HS S-domain-negative tissue was stained with the 10E4 anti-HS antibody that requires $\mathrm{N}$-sulfated glucosamine. ${ }^{50}$ Several punctate TTR deposits colocalized with the 10E4 signal, whereas relatively large deposits were negative for 10E4 staining (Supplemental Figure S1), which suggests the existence of an alternative aggregation pathway in addition to those that involve sulfated GAGs. Two of the three patients who received liver transplantation were positive for both TTR deposits and HS S-domains (Figure 1C).
Heparin Accelerates Fibril Formation by TTR Fragments in an S-Domain-Dependent Manner

Many studies reported that heparin, which is a structural analog of HS S-domains, enhanced amyloid formation or protein aggregation by various amyloidogenic proteins. ${ }^{23}$ We investigated whether HS S-domains would facilitate fibril formation by various TTR fragments. The aggregation propensity prediction tool AmylPred2 ${ }^{51}$ was used with TTR. On the basis of the results, three TTR fragments (ie, the fragment with amino acid residues 12 to 35 , where the heparin-binding motif is located ${ }^{4}$; the fragment with amino acid residues 12 to 35 carrying the V30M mutation; and the C-terminal fragment with amino acid residues 105 to 123 , which were shown to be the major depositing fragments in patients with ATTR amyloidosis) were used (Supplemental Figure S2). ${ }^{52}$ Fibril formations of these three fragments, which were analyzed by using the amyloidophilic ThT dye, were enhanced within 30 to 50 minutes of incubation in the wells of heparin-BSA-coated plates (Figure 2A). It was then investigated whether the HS S-domain is critical for enhancing fibril formation by TTR fragments. To degrade the HS S-domains in these plates, immobilized heparin was 
preincubated with concentrated culture medium of $\mathrm{CHO}$ cells that stably express HSulf-2. Elimination of HS Sdomains was confirmed by using an enzyme-linked immunosorbent assay with RB4CD12 antibody (Figure 2B). Fibril formation by TTR fragments in these HS Sdomain-eliminated plates was suppressed in 75 minutes from the beginning of the assay compared with that in plates that were treated with the conditioned medium of control CHO cells (the 12 to 35 fragment, 20\%; the 12 to 35 mutated fragment, 5\%; and the 105 to 123 fragment, $40 \%$ ) (Figure 2C). Sulf-2 pretreatment completely abolished the fibril formation of TTR12-35/V30M (Figure 2C). These results clearly indicate that HS S-domains are critical for fibril formation accelerated by heparin. The ThT intensity began to decrease after an incubation time of approximately 4 hours (Figure 2C), possibly because of the absorption of fibrils to the wall of the well. However, ThT intensities were 1.5 (TTR 105 to 123 ) to 10 (TTR 12 to 35 ) times higher in the mock-treated groups than in the HSulf-2-treated groups, which supports the importance of HS S-domains.

\section{HSulf-2 Interferes with Interactions of Cells with TTR Fibrils and Cytotoxicity of TTR Fragments}

A HSulf-2 stably expressing variant of $\mathrm{CHO}$ cells whose HS S-domains were reduced to approximately $20 \%$ to $50 \%$ of those of mock-transfected cells ${ }^{40}$ was previously used, and it was found that the interactions of cells with fibrils of apoA-I fragments and cytotoxicity of these fibrils depended on HS S-domains at the cell surface. ${ }^{20}$ Because fibrils of the TTR fragments that were used herein cannot be detected by immunocytochemical analysis or immunoblotting, fluorescently labeled TTR fibrils were used to analyze their interactions with cells. CHO cells and HSulf-2-expressing cells were then treated, after which the percentages of TTR fibril-positive cells were calculated. Formation of TTR
A
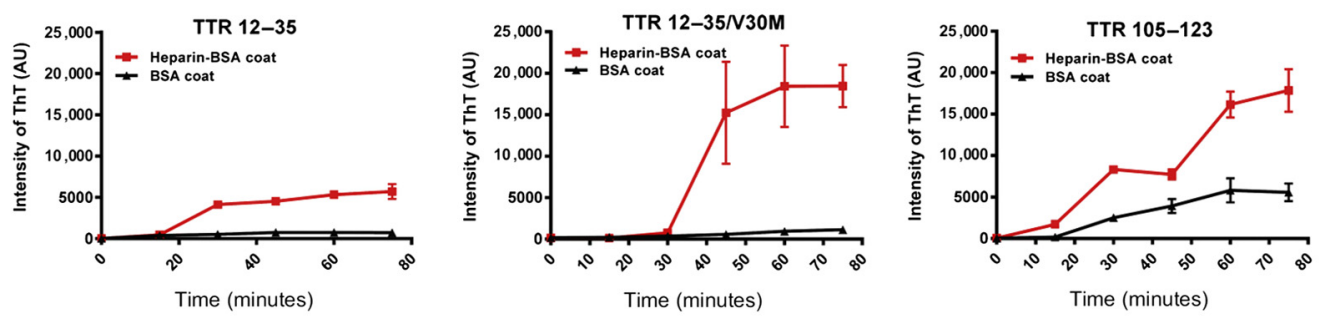

B

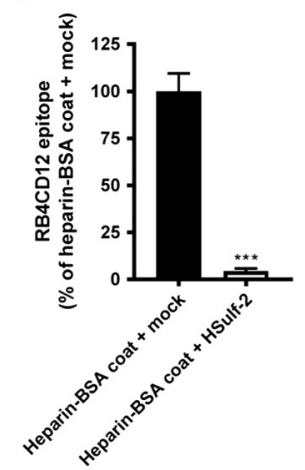

\section{C}
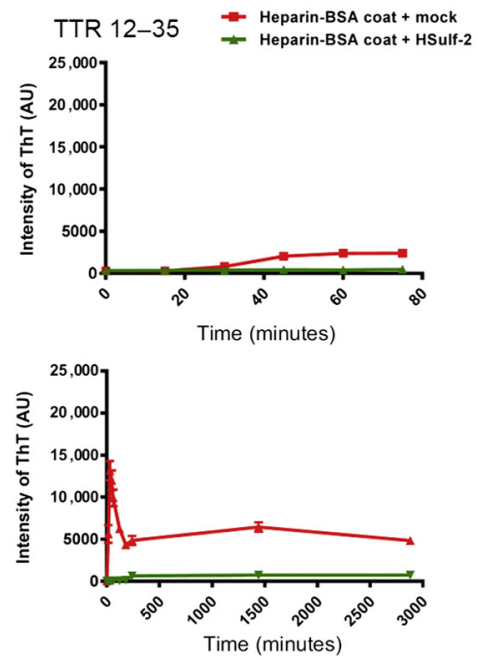
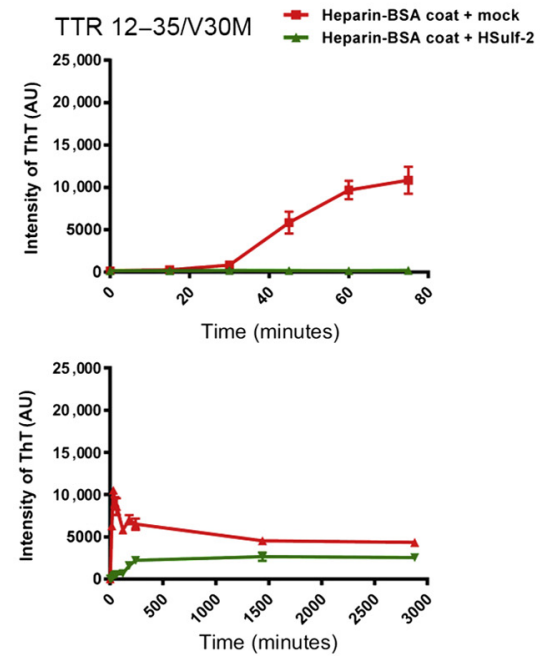
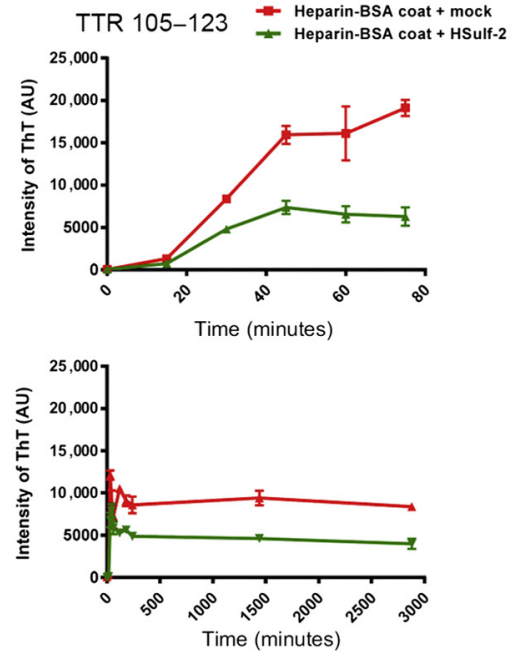

Figure 2 Heparin promotes fibril formation by TTR fragments in an HS S-domain-dependent manner. A: Fibril formation in bovine serum albumin (BSA)coatedor heparin-BSA-coated plates was determined by using the fluorescence-detected thioflavin T (ThT)-binding assay. B: To degrade HS S-domains within heparin chains, wells of heparin-BSA-coated plates were preincubated with HSulf-2-conditioned medium prepared from Chinese hamster ovary (CH0) cells that stably express HSulf-2. Elimination of HS S-domains was confirmed by using an enzyme-linked immunosorbent assay with the anti-S-domain antibody RB4CD12. C: Conditioned medium prepared from $\mathrm{CHO}$ cells that stably express a mock vector was used as a control. Fibril formation by TTR fragments markedly decreases after HS S-domains in immobilized heparin were removed. Left column: Fibril formation in heparin-BSA -coated plates was monitored for 75 minutes. Right column: Fibril formation in heparin-BSA-coated plates was monitored for 48 hours. Data are expressed as means \pm SEM (no error bars appear when the error bars are smaller than the sizes of the symbols). $n=5$ (A and $\mathbf{C}) ; n=3(\mathbf{B})$. ${ }^{* * *} p<0.001$ versus + mock. AU, arbitrary unit. 
fibrils of these fragments was confirmed by using AFM (Figure 3A). The percentages of TTR fibril-positive cells were $50 \%$ to $75 \%$ and $20 \%$ to $25 \%$ in CHO and HSulf2-expressing cells, respectively (Figure 3B). Contacts of these TTR fibrils with $\mathrm{CHO}$ cells significantly decreased as a result of the reduction in HS S-domains at the cell surface (Figure 3B). Also, interactions of TTR fibrils with cells were mediated by HS S-domains independently of the V30M mutation. Cytotoxicity of apoA-I fibrils (ie, induction of mitochondrial depolarization) depends on HS S-domains. ${ }^{20}$ It was studied whether TTR fibrils caused the cytotoxicity. TTR fibrils caused mitochondrial depolarization in cells, as measured with the mitochondrial potential-sensitive tetramethylrhodamine, ethyl ester, dye (Figure 3C), which indicates that HS S-domains mediated interactions of cells with TTR fibrils and the cytotoxicity of these TTR fibrils regardless of the TTR mutation or the TTR fragment.

\section{GPC5 Accumulates in the ATTR Amyloidosis Kidney and Increases in Mesangial Cells after TTR Fibril Treatment}

A major cause of death in various systemic amyloidoses, including ATTR amyloidosis, is kidney dysfunction. ${ }^{37}$ Okamoto et $\mathrm{al}^{42}$ identified GPC5, a member of the heparan sulfate proteoglycan family, as a susceptible gene for acquired nephrotic syndrome and showed that GPC5 mediated the harmful effects of excessive FGF2 on glomeruli. ${ }^{53}$ As an interesting result, colocalization of GPC5 and HS S-domains was observed in the glomeruli of a patient with ATTR amyloidosis (Figure 4A). No signals were observed when control tissues were stained with an isotype rabbit $\operatorname{IgG}$ or an isotype mouse IgG (Supplemental Figure S3). Because GPC5 in the kidney is expressed by mesangial cells and podocytes ${ }^{42}$ the effect of TTR fibrils on expression of GPC5 was next studied in cultured mesangial cells and podocytes. The expression of GPC5 in mesangial cells, but not in podocytes, was enhanced by treatment with fibrils of C-terminal fragments of TTR, which often accumulated in patients' tissues or organs (Figure 4B). ${ }^{52}$ In addition, HS S-domains coimmunoprecipitated with GPC5 in TTR fibril-treated mesangial cells (Figure 4C), which suggests that GPC5 is a candidate core protein of HS S-domains in mesangial cells. Increased GPC5 induced glomerular accumulation of FGF2. ${ }^{53}$ In agreement with that result, accumulation of FGF2 and its colocalization with GPC5 and TTR deposits was seen in glomeruli of a patient with ATTR amyloidosis (Figure 5 and Supplemental Figure S4).

\section{Discussion}

Since the identification of HS as a codeposited component of tissue amyloid in experimental AA amyloidosis, ${ }^{9}$ certain studies have suggested that HS affects the

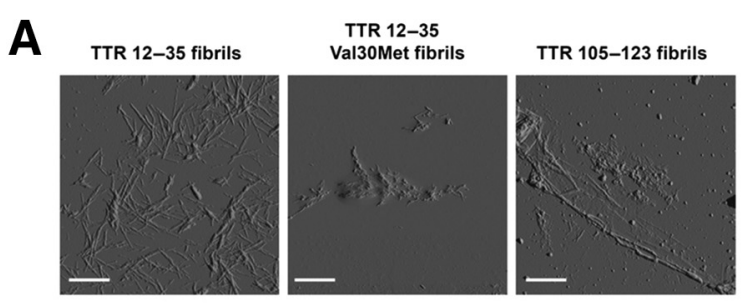

B
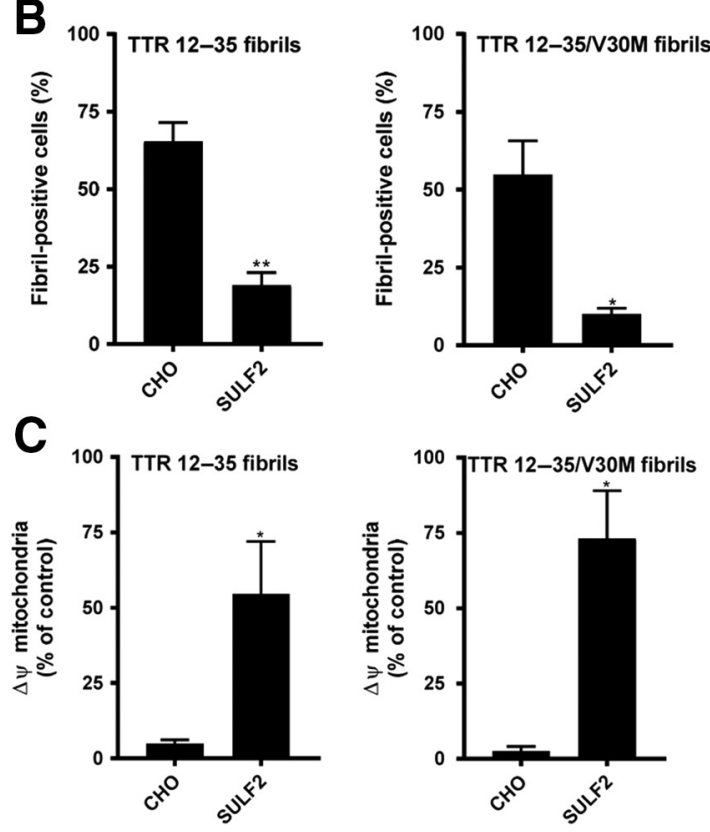

Figure 3 Stable expression of HSulf-2 inhibits interactions of cells with TTR fibrils and cytotoxicity of fibrils of TTR fragments. A: Atomic force microscopy (AFM) images of TTR fibrils formed by the wild-type and V30M mutant TTR 12 to 35 fragments and the 105 to 123 fragments. TTR fibrils were obtained by incubating these TTR fragments $(30 \mu \mathrm{mol} / \mathrm{L})$ at $37^{\circ} \mathrm{C}$ for 7 days, after which the AFM analysis was performed. B: Nontransfectant Chinese hamster ovary ( $\mathrm{CHO}$ ) cells ( $\mathrm{CHO}$ ) and transfectants that stably expressed HSulf-2 (SULF2) were plated on poly-L-lysine-coated coverslips, treated with $1 \mu \mathrm{mol} / \mathrm{L}$ TTR fibrils that were fluorescently labeled, and examined with a confocal microscope. Percentages of TTR fibril-positive CHO and SULF2 cells were determined. C: Nontransfected and HSulf-2-transfected $\mathrm{CHO}$ cells were seeded onto 24-well plates and treated with $1 \mu \mathrm{mol} / \mathrm{L}$ TTR fibrils, after which the membrane potential of mitochondria was analyzed by using tetramethylrhodamine, ethyl ester, dye. The graphs show the percentages of cells with depolarized mitochondria. The control is the result for cells treated with the same amounts of phosphate-buffered saline as those used for cells treated with TTR fibrils. Data are expressed as means \pm SEM (B and C). $n=3$ independent experiments (B and $\mathbf{C}) .{ }^{*} P<0.05,{ }^{*} P<0.01$ versus nontransfectants. Scale bars $=2 \mu \mathrm{m}(\mathbf{A})$. 
A

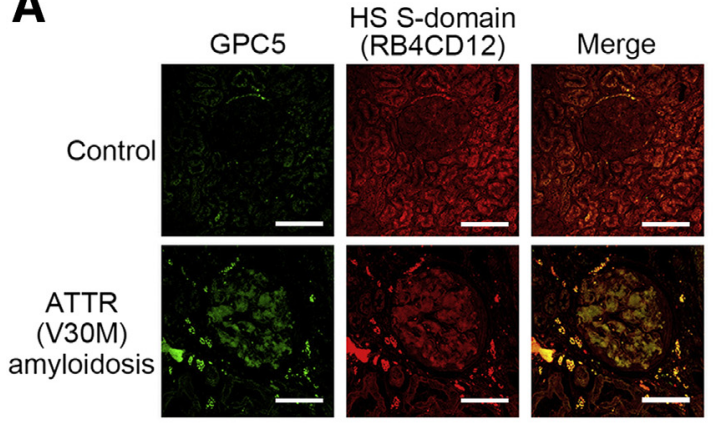

B
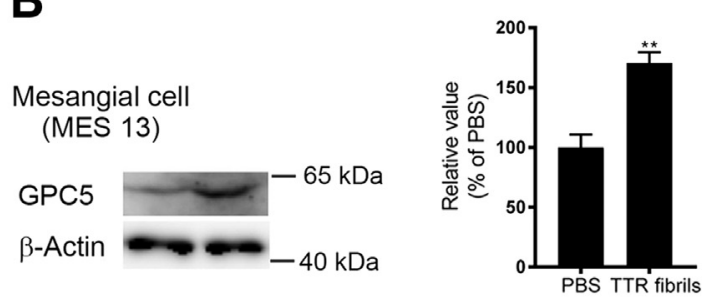

Podocyte
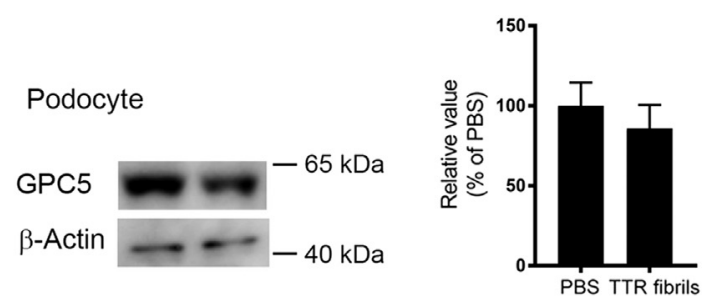

C

Mesangial cell (MES 13)

IB: RB4CD12

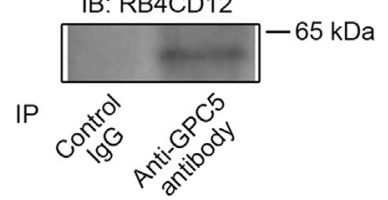

Figure 4 Accumulation of glypican-5 (GPC5) in the ATTR amyloidosis kidney and effects of TTR fibrils on GPC5 expression in kidney cells. A: Amyloid-positive sections were stained with an anti-GPC5 antibody (green) and the RB4CD12 antibody (red). GPC5 accumulates in the ATTR amyloidosis kidney and colocalizes with HS S-domains. Postmortem kidney sections prepared from subjects without amyloidosis were also used (Control). B: Immortalized human podocytes and mesangial cells were cultured and then treated with $1 \mu \mathrm{mol} / \mathrm{L}$ TTR fibrils for 24 hours, after which levels of GPC5 protein were analyzed by means of Western blot analysis. The graphs show quantification of GPC5. TTR fibril treatment enhances expression of GPC5 in mesangial cells but not in podocytes. C: HS S-domains in TTR fibril-treated cells immunoprecipitate together with the anti-GPC5 antibody in MES 13 cells. Cells that were treated with TTR fibrils were homogenized by sonication in radioimmunoprecipitation assay buffer containing a protease inhibitor cocktail followed by centrifugation at $1000 \times g$ for 20 minutes at $4^{\circ} \mathrm{C}$. Supernatants were harvested; GPC5-HS S-domain complexes were immunoprecipitated with an antiGPC5 antibody; and HS S-domains in the immunoprecipitants were detected by Western blot analysis with the RB4CD12 antibody. Data are expressed as means \pm SEM (B). $n=3$ independent experiments (B). ${ }^{* * P}<0.01$ versus nontreated cells. Scale bars $=50 \mu \mathrm{m}(\mathbf{A})$. IB, immunoblot; IP, immunoprecipitation; PBS, phosphate-buffered saline. aggregation of various amyloidogenic proteins. ${ }^{23}$ The ability of HS and/or heparin to promote protein aggregation depended on the degree of sulfation. However, the involvement of an S-domain, which is highly sulfated and a key element in the biological functions of HS, in systemic amyloidosis has never been addressed. Herein, we showed that HS S-domains colocalized with TTR amyloid deposits in tissues from patients with ATTR amyloidosis. The ability of heparin to promote aggregation of various TTR fragments was reduced by eliminating HS S-domains in polysaccharide chains, which suggests that heparinmediating fibril formation of TTR fragments depended on HS S-domains. Given that HS or heparin serves as a scaffold by collecting monomers and promotes aggregation of a model peptide for amyloidogenic proteins, ${ }^{54}$ our results strongly suggest that HS S-domains play a central role in collecting the monomers of the $\mathrm{N}$-terminal fragment of TTR that have a heparin-binding motif. ${ }^{4}$ Aggregation of the C-terminal fragment of TTR was observed without heparin within 20 minutes and was accelerated by heparin. Thus, although the C-terminal fragment of TTR does not include a heparin-binding site, ${ }^{4}$ denatured small intermediates or seeds for aggregation may acquire a heparin-binding ability via conformational changes, and the subsequent aggregation process may depend on HS Sdomains. Also, the C-terminal 49 to 127 fragments that are released by a proteolytic cleavage are highly amyloidogenic. ${ }^{55}$ Elucidation of the molecular mechanism of TTR aggregation in the presence of heparin is a challenge for the future.

HS also mediates interactions of cells with protein aggregates. For example, HS is a primary receptor for infectious prion, ${ }^{56-58}$ and HS at the cell surface mediated A $\beta$ cytotoxicity. ${ }^{19} \mathrm{HS}$, and especially its HS S-domains, mediates interactions of cells with apoA-I fibrils. ${ }^{20}$ These results indicate a potential role of HS S-domains in interactions of cells with protein aggregates or uptake of protein aggregates. Also, in the present study, elimination of HS S-domains by HSulf-2 markedly decreased interactions of cells with TTR fibrils, which suggests that HS S-domains are critical for interactions of cells with TTR fibrils as well as for fibril formation. Although the C-terminal TTR fragment reportedly lacks heparin-binding ability, ${ }^{4}$ interactions of the C-terminal TTR fragment fibrils with cells and the subsequent cytotoxicity were reduced by HSulf-2, which suggests that fibrils of the C-terminal TTR fragment acquired heparin-binding ability by aggregating into amyloid fibrils. The G26R variant apoA-I forms fibrils in a heparin-independent manner, ${ }^{59}$ and its interactions with cells and cytotoxicity depend on HS S-domains at the cell surface. ${ }^{20}$ These lines of evidence suggest that binding molecules of amyloid fibrils before and after fibril formation may differ.

TTR exists physiologically as a tetramer with only a small amount of monomer, ${ }^{60}$ and the initial step of TTR aggregation is dissociation of TTR tetramers into monomers. ${ }^{33}$ With regard to serum AA, Noborn et $\mathrm{al}^{61}$ reported 


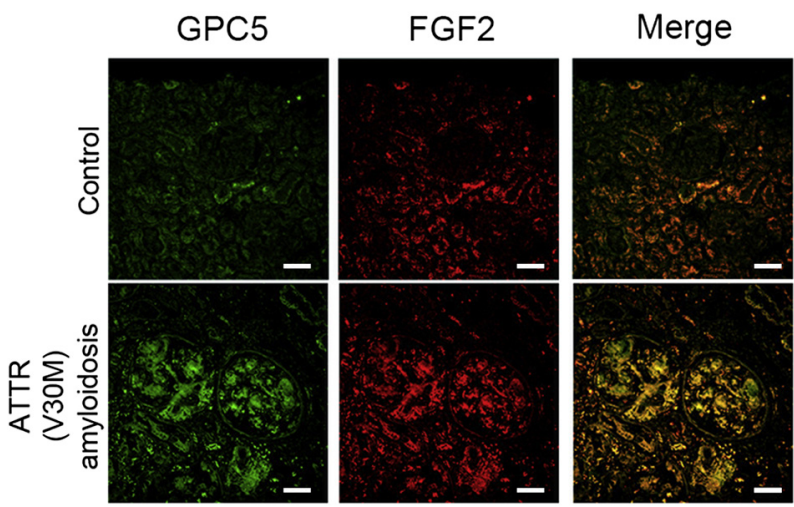

Figure 5 Fibroblast growth factor 2 (FGF2) accumulates in the kidney of a 38-year-old patient with V30M ATTR amyloidosis. Renal sections were stained with an anti-FGF2 antibody (red) and an anti-glypican-5 (GPC5) antibody (green). GPC5 staining colocalizes with FGF2 staining in the glomeruli (Merge). Scale bars $=50 \mu \mathrm{m}$.

that HS dissociated serum AA from high-density lipoprotein and thereby promoted serum AA aggregation. Thus, whether HS and heparin affect the stability of TTR tetramers is also of interest. Several tissues and organs, including the kidney, are enriched with HS and HS S-domains regardless of the presence of amyloid deposits, and Sulfs are at least partly involved in the expression of HS S-domains. ${ }^{62}$ Because these results suggest that HS S-domains accelerated TTR aggregation and mediated the cytotoxicity of TTR fragments, analysis of the disaccharide compositions and Sulf levels in various tissues and organs with or without amyloid deposits will broaden the current understanding of the role of HS S-domains in amyloidoses.

Although the principal manifestation of most ATTR amyloidoses is peripheral neuropathy, the kidney is also a main organ with amyloid deposition in ATTR amyloidosis. ${ }^{63}$ The clinical manifestations range from proteinuria to endstage renal failure, although proteinuria is the most frequent manifestation. ${ }^{64,65}$ Proteinuria has been well established as resulting from defects in the glomerular filtration barrier. ${ }^{66}$ Although the mechanisms of organ dysfunction in amyloidosis include physical disruption of tissues that is caused by accumulation of amyloid fibrils in the extracellular spaces and direct cytotoxicity of the amyloid fibrils or oligomers, ${ }^{36}$ some common structural defects may occur in diabetes and amyloidosis-related renal dysfunction. ${ }^{67}$ Okamoto et $\mathrm{al}^{42}$ identified GPC5 as a novel gene that is involved in the susceptibility to acquired nephrotic syndrome. They also showed that podocyte-specific knockdown of GPC5 prevented podocyte injury in mouse models of nephrosis. Herein, we showed that GPC5 accumulated in glomeruli of a patient with ATTR amyloidosis, which strongly suggests that GPC5 may be involved in renal dysfunction in this disorder. GPC5 is an HS-carrying proteoglycan and one of the six members of the glycosylphosphatidylinositol-anchored glypican family. ${ }^{68}$ Because GPC5 can be cleaved, ${ }^{69}$ membrane-anchored GPC5 may be released and may accumulate in glomerular
TTR deposits. One of the core proteins of HS S-domains that codeposit with TTR amyloid may be GPC5. The kidney and glomeruli express other core proteins of proteoglycans, including those of the extracellular matrix. Additional studies to identify the other core proteins are absolutely necessary.

FGF2 is a highly conserved cationic protein and is released from cytoplasmic storage sites in response to cell injury. In the kidney, FGF2 is reportedly synthesized by glomerular mesangial cells ${ }^{70}$ and podocytes, ${ }^{71}$ and it stimulates proliferation of these cells in vitro. Optimal activities of FGF2 require glypicans, ${ }^{72}$ including GPC5. ${ }^{73}$ Although FGF2 stimulated proliferation of glomerular mesangial cells, endothelial cells, and podocytes, ${ }^{71,74,75}$ an excess amount of FGF2 was harmful to glomeruli and induced proteinuria. ${ }^{76,77}$ Podocyte-specific knockdown of GPC5 has also reduced FGF2-induced podocyte injury and proteinuria by inhibiting FGF2 binding to cells. ${ }^{42}$ Thus, the accumulation of both GPC5 and FGF2 in glomeruli of patients with ATTR amyloidosis, as observed herein, indicates that hyperactivation of FGF2 signaling via GPC5 may have a role in amyloid nephropathy in ATTR amyloidosis. The mechanism by which accumulation of GPC5 and FGF2 was induced is currently unknown. GPC5 may have accumulated as a core protein of the HS S-domains that also occurred in glomeruli with amyloid. FGF2 was released after cell damage, ${ }^{78}$ so podocytes or mesangial cells may also release FGF2 in response to amyloid fibril-induced cell damage. Although FGF2 gene transfer reportedly restored hippocampal functions in an AD mouse model,${ }^{79}$ the roles of FGF2 signaling in other systemic and localized amyloidoses remain to be elucidated. Additional studies to clarify these mechanisms are essential before considering GPC5 and FGF2 as therapeutic targets in amyloid nephropathy in ATTR amyloidosis. Inasmuch as the kidney is a common target in several systemic amyloidoses, addressing the involvement of GPC5 and FGF2 in amyloid nephropathy that occurs in other amyloidoses would also be of interest.

Sulf-2 is an enzyme that remodels HS extracellularly by removing 6-O-sulfate groups on glucosamine residues in the HS S-domains within heparin and HS. ${ }^{40,80}$ A previous knockout study suggested that Sulf-2 contributed to the occurrence and maintenance of specific sulfation patterns of HS in various organs, such as the kidney ${ }^{62}$ which is one of the major sites and targets for amyloid deposition and amyloid-related damage in several systemic amyloidoses, including ATTR amyloidosis. Transfectant $\mathrm{CHO}$ cells that stably express HSulf-1 or HSulf-2 interact less with Iowa mutation of apoA-I fibrils compared with nontransfectant $\mathrm{CHO}$ cells. ${ }^{20}$ On the basis of the finding that HS S-domains that were degraded by Sulf- 2 accumulated in senile plaques in AD patients, ${ }^{22}$ we proposed that enzymatic remodeling of HS by Sulf- 2 may modulate the pathogenesis or pathology of localized and systemic amyloidoses, such as $\mathrm{AD}$ and Iowa mutation of apoA-I amyloidosis. ${ }^{43}$ With regard to FGF, FGF signaling requires heparan sulfate proteoglycans to form stable ligand/receptor complexes,${ }^{81}$ because the 
6-O-sulfate group of heparin and HS plays a critical role in FGF-FGF receptor binding and dimerization of the FGF receptor. $^{82,83}$ Thus, our study supports the idea that enzymatic remodeling of HS may affect not only deposition of amyloid fibrils but also clinical manifestations in amyloidoses via modulating various signaling pathways, including FGF signaling. Our results also lead us to propose that the activity or protein levels of endogenous Sulf-2 may be involved in the pathogenesis, progression, and clinical manifestation of amyloidoses. The correlation between Sulf-2 and GPC5 is currently not clear. The finding showing accumulation of HS S-domains in kidneys of ATTR patients suggests that Sulf-2 activity may be affected in ATTR amyloidosis. Because reports have shown that Sulf-2 negatively regulates and GPC5 positively regulates FGF2 signaling, ${ }^{41,73}$ additional studies are required.

On the basis of these results, we therefore propose that HS S-domains, which can be enzymatically remodeled by Sulf-2, act as a scaffold for formation of TTR fibrils and mediate interactions of the fibrils with cells. Our idea of modulating amyloid deposition and clinical symptoms by enzymatic remodeling is not limited to ATTR amyloidosis but can be applied to various systemic and localized amyloidoses. The glomerular accumulation of GPC5 and FGF2 suggested hyperactivation of FGF2 signaling, which is an attractive candidate as a therapeutic target in renal dysfunction in systemic amyloidoses. Additional studies to confirm these possibilities are needed. Amyloid deposits were observed in the mesangium and capillary walls, but the mechanism by which TTR or TTR fibrils pass through the endothelial barrier and reach the mesangium is currently unknown. With regard to $A \beta$, Marco and $\mathrm{Skaper}^{84}$ suggested that $A \beta$ has a detrimental effect on the endothelial barrier at the brain-blood barrier. Effects of amyloid fibrils on endothelial cells are also yet to be clarified. Finally, the contents of HS S-domains vary among tissues, organs, and various types of cells. Determining the HS S-domain contents in various tissues, organs, and cells and using tissuederived HS may provide clues to understanding the tissue specificity of deposition and damage by amyloid fibrils.

\section{Acknowledgments}

We thank Tomoki Yoshioka for technical help, the Support Center for Advanced Medical Sciences (Institute of Biomedical Sciences, Tokushima University), and Dr. Toin H. van Kuppevelt (Nijmegen Center for Molecular Life Sciences, Radboud University Nijmegen Medical Center, Nijmegen, the Netherlands) for providing RB4CD12 antibody.

H.K., K.K., T.M., T.K., and K.O. performed the experiments; M.M. prepared the C-terminal fragments or transthyretin and interpreted the data; S.-C.H. prepared the heparin-bovine serum albumin conjugates and interpreted the data; T.O. and H.S. performed the atomic force microscopy analysis; T.Y. and Y.A. performed the immunohistochemical analysis; K.U. interpreted the data and supervised the entire project; K.N. designed the study, interpreted the data, wrote the article, and takes full responsibility for the article; all authors reviewed the results and approved the final version of the article.

\section{Supplemental Data}

Supplemental material for this article can be found at https://doi.org/10.1016/j.ajpath.2018.09.015.

\section{References}

1. Lyon M, Gallagher JT: Bio-specific sequences and domains in heparan sulphate and the regulation of cell growth and adhesion. Matrix Biol 1998, 17:485-493

2. Gallagher JT: Heparan sulfate: growth control with a restricted sequence menu. J Clin Invest 2001, 108:357-361

3. Esko JD, Selleck SB: Order out of chaos: assembly of ligand binding sites in heparan sulfate. Annu Rev Biochem 2002, 71:435-471

4. Noborn F, O'Callaghan P, Hermansson E, Zhang X, Ancsin JB, Damas AM, Dacklin I, Presto J, Johansson J, Saraiva MJ, Lundgren E, Kisilevsky R, Westermark P, Li JP: Heparan sulfate/heparin promotes transthyretin fibrillization through selective binding to a basic motif in the protein. Proc Natl Acad Sci U S A 2011, 108:5584-5589

5. Snow AD, Mar H, Nochlin D, Kimata K, Kato M, Suzuki S, Hassell J, Wight TN: The presence of heparan sulfate proteoglycans in the neuritic plaques and congophilic angiopathy in Alzheimer's disease. Am J Pathol 1988, 133:456-463

6. Snow AD, Mar H, Nochlin D, Sekiguchi RT, Kimata K, Koike Y, Wight TN: Early accumulation of heparan sulfate in neurons and in the beta-amyloid protein-containing lesions of Alzheimer's disease and Down's syndrome. Am J Pathol 1990, 137:1253-1270

7. van Horssen J, Kleinnijenhuis J, Maass CN, Rensink AA, OtteHoller I, David G, van den Heuvel LP, Wesseling P, de Waal RM, Verbeek MM: Accumulation of heparan sulfate proteoglycans in cerebellar senile plaques. Neurobiol Aging 2002, 23:537-545

8. Young ID, Willmer JP, Kisilevsky R: The ultrastructural localization of sulfated proteoglycans is identical in the amyloids of Alzheimer's disease and AA, AL, senile cardiac and medullary carcinomaassociated amyloidosis. Acta Neuropathol 1989, 78:202-209

9. Snow AD, Kisilevsky R: Temporal relationship between glycosaminoglycan accumulation and amyloid deposition during experimental amyloidosis: a histochemical study. Lab Invest 1985, 53: $37-44$

10. Bourgault S, Solomon JP, Reixach N, Kelly JW: Sulfated glycosaminoglycans accelerate transthyretin amyloidogenesis by quaternary structural conversion. Biochemistry 2011, 50:1001-1015

11. Castillo GM, Lukito W, Wight TN, Snow AD: The sulfate moieties of glycosaminoglycans are critical for the enhancement of beta-amyloid protein fibril formation. J Neurochem 1999, 72:1681-1687

12. McLaurin J, Franklin T, Zhang X, Deng J, Fraser PE: Interactions of Alzheimer amyloid-beta peptides with glycosaminoglycans effects on fibril nucleation and growth. Eur J Biochem 1999, 266:1101-1110

13. Bravo R, Arimon M, Valle-Delgado JJ, Garcia R, Durany N, Castel S, Cruz M, Ventura S, Fernandez-Busquets X: Sulfated polysaccharides promote the assembly of amyloid beta(1-42) peptide into stable fibrils of reduced cytotoxicity. J Biol Chem 2008, 283: 32471-32483

14. Blancas-Mejia LM, Hammernik J, Marin-Argany M, RamirezAlvarado M: Differential effects on light chain amyloid formation depend on mutations and type of glycosaminoglycans. J Biol Chem 2015, 290:4953-4965 
15. Ancsin JB, Kisilevsky R: The heparin/heparan sulfate-binding site on apo-serum amyloid A: implications for the therapeutic intervention of amyloidosis. J Biol Chem 1999, 274:7172-7181

16. Takase H, Tanaka M, Yamamoto A, Watanabe S, Takahashi S, Nadanaka S, Kitagawa H, Yamada T, Mukai T: Structural requirements of glycosaminoglycans for facilitating amyloid fibril formation of human serum amyloid A. Amyloid 2016, 23:67-75

17. Aguilera JJ, Zhang F, Beaudet JM, Linhardt RJ, Colon W: Divergent effect of glycosaminoglycans on the in vitro aggregation of serum amyloid A. Biochimie 2014, 104:70-80

18. Holmes BB, DeVos SL, Kfoury N, Li M, Jacks R, Yanamandra K, Ouidja MO, Brodsky FM, Marasa J, Bagchi DP, Kotzbauer PT, Miller TM, Papy-Garcia D, Diamond MI: Heparan sulfate proteoglycans mediate internalization and propagation of specific proteopathic seeds. Proc Natl Acad Sci U S A 2013, 110: E3138-E3147

19. Sandwall E, O'Callaghan P, Zhang X, Lindahl U, Lannfelt L, Li JP: Heparan sulfate mediates amyloid-beta internalization and cytotoxicity. Glycobiology 2010, 20:533-541

20. Kuwabara K, Nishitsuji K, Uchimura K, Hung SC, Mizuguchi M, Nakajima H, Mikawa S, Kobayashi N, Saito H, Sakashita N: Cellular interaction and cytotoxicity of the Iowa mutation of apolipoprotein AI (ApoA-IIowa) amyloid mediated by sulfate moieties of heparan sulfate. J Biol Chem 2015, 290:24210-24221

21. Bruinsma IB, te Riet L, Gevers T, ten Dam GB, van Kuppevelt TH, David G, Kusters B, de Waal RM, Verbeek MM: Sulfation of heparan sulfate associated with amyloid-beta plaques in patients with Alzheimer's disease. Acta Neuropathol 2010, 119:211-220

22. Hosono-Fukao T, Ohtake-Niimi S, Hoshino H, Britschgi M, Akatsu H, Hossain MM, Nishitsuji K, van Kuppevelt TH, Kimata K, Michikawa M, Wyss-Coray T, Uchimura K: Heparan sulfate subdomains that are degraded by Sulf accumulate in cerebral amyloid $B$ plaques of Alzheimer's disease: evidence from mouse models and patients. Am J Pathol 2012, 180:2056-2067

23. Nishitsuji K, Uchimura K: Sulfated glycosaminoglycans in protein aggregation diseases. Glycoconj J 2017, 34:453-466

24. Nishitsuji K: Heparan sulfate S-domains and extracellular sulfatases (Sulfs): their possible roles in protein aggregation diseases. Glycoconj J 2018, [Epub ahead of print] doi:10.1007/s10719-018-9833-8

25. Eanes ED, Glenner GG: X-ray diffraction studies on amyloid filaments. J Histochem Cytochem 1968, 16:673-677

26. Sipe JD, Benson MD, Buxbaum JN, Ikeda S, Merlini G, Saraiva MJ, Westermark P: Nomenclature 2014: amyloid fibril proteins and clinical classification of the amyloidosis. Amyloid 2014, 21:221-224

27. Connors LH, Lim A, Prokaeva T, Roskens VA, Costello CE: Tabulation of human transthyretin (TTR) variants, 2003. Amyloid 2003, 10:160-184

28. Raz A, Shiratori T, Goodman DS: Studies on the protein-protein and protein-ligand interactions involved in retinol transport in plasma. J Biol Chem 1970, 245:1903-1912

29. Saraiva MJ, Birken S, Costa PP, Goodman DS: Amyloid fibril protein in familial amyloidotic polyneuropathy, Portuguese type: definition of molecular abnormality in transthyretin (prealbumin). J Clin Invest 1984, 74:104-119

30. Buxbaum J, Koziol J, Connors LH: Serum transthyretin levels in senile systemic amyloidosis: effects of age, gender and ethnicity. Amyloid 2008, 15:255-261

31. Ando Y, Coelho T, Berk JL, Cruz MW, Ericzon BG, Ikeda S, Lewis WD, Obici L, Plante-Bordeneuve V, Rapezzi C, Said G, Salvi F: Guideline of transthyretin-related hereditary amyloidosis for clinicians. Orphanet J Rare Dis 2013, 8:31

32. Teng MH, Yin JY, Vidal R, Ghiso J, Kumar A, Rabenou R, Shah A, Jacobson DR, Tagoe C, Gallo G, Buxbaum J: Amyloid and nonfibrillar deposits in mice transgenic for wild-type human transthyretin: a possible model for senile systemic amyloidosis. Lab Invest 2001, 81:385-396

33. Buxbaum JN, Reixach N: Transthyretin: the servant of many masters. Cell Mol Life Sci 2009, 66:3095-3101
34. Theis JD, Dasari S, Vrana JA, Kurtin PJ, Dogan A: Shotgun-proteomics-based clinical testing for diagnosis and classification of amyloidosis. J Mass Spectrom 2013, 48:1067-1077

35. Kisilevsky R, Ancsin JB, Szarek WA, Petanceska S: Heparan sulfate as a therapeutic target in amyloidogenesis: prospects and possible complications. Amyloid 2007, 14:21-32

36. Dember LM: Amyloidosis-associated kidney disease. J Am Soc Nephrol 2006, 17:3458-3471

37. Lobato L, Rocha A: Transthyretin amyloidosis and the kidney. Clin J Am Soc Nephrol 2012, 7:1337-1346

38. Farquhar M: The glomerular basement membrane: a selective macromolecular filter. Edited by Hay ED. In Cell Biology of the Extracellular Matrix. ed 2. New York: Plenum Press, 1991. pp. 365-412

39. Dennissen MA, Jenniskens GJ, Pieffers M, Versteeg EM, Petitou M, Veerkamp JH, van Kuppevelt TH: Large, tissue-regulated domain diversity of heparan sulfates demonstrated by phage display antibodies. J Biol Chem 2002, 277:10982-10986

40. Hossain MM, Hosono-Fukao T, Tang R, Sugaya N, van Kuppevelt TH, Jenniskens GJ, Kimata K, Rosen SD, Uchimura K: Direct detection of HSulf-1 and HSulf-2 activities on extracellular heparan sulfate and their inhibition by PI-88. Glycobiology 2010, 20:175-186

41. Rosen SD, Lemjabbar-Alaoui H: Sulf-2: an extracellular modulator of cell signaling and a cancer target candidate. Expert Opin Ther Targets 2010, 14:935-949

42. Okamoto K, Tokunaga K, Doi K, Fujita T, Suzuki H, Katoh T, Watanabe T, Nishida N, Mabuchi A, Takahashi A, Kubo M, Maeda S, Nakamura Y, Noiri E: Common variation in GPC5 is associated with acquired nephrotic syndrome. Nat Genet 2011, 43:459-463

43. Nishitsuji K, Saito H, Uchimura K: Enzymatic remodeling of heparan sulfate: a therapeutic strategy for systemic and localized amyloidoses? Neural Regen Res 2016, 11:408-409

44. Saleem MA, O'Hare MJ, Reiser J, Coward RJ, Inward CD, Farren T, Xing CY, Ni L, Mathieson PW, Mundel P: A conditionally immortalized human podocyte cell line demonstrating nephrin and podocin expression. J Am Soc Nephrol 2002, 13:630-638

45. Najjam S, Gibbs RV, Gordon MY, Rider CC: Characterization of human recombinant interleukin 2 binding to heparin and heparan sulfate using an ELISA approach. Cytokine 1997, 9:1013-1022

46. Naiki H, Higuchi K, Hosokawa M, Takeda T: Fluorometric determination of amyloid fibrils in vitro using the fluorescent dye, thioflavin T1. Anal Biochem 1989, 177:244-249

47. Nakajima H, Nishitsuji K, Kawashima H, Kuwabara K, Mikawa S, Uchimura K, Akaji K, Kashiwada Y, Kobayashi N, Saito H Sakashita N: The polyphenol (-)-epigallocatechin-3-gallate prevents apoA-IIowa amyloidosis in vitro and protects human embryonic kidney 293 cells against amyloid cytotoxicity. Amyloid 2016, 23:17-25

48. Uchimura K, Morimoto-Tomita M, Bistrup A, Li J, Lyon M, Gallagher J, Werb Z, Rosen SD: HSulf-2, an extracellular endoglucosamine-6sulfatase, selectively mobilizes heparin-bound growth factors and chemokines: effects on VEGF, FGF-1, and SDF-1. BMC Biochem 2006, 7:2

49. Puchtler H, Sweat F: Congo red as a stain for fluorescence microscopy of amyloid. J Histochem Cytochem 1965, 13:693-694

50. David G, Bai XM, Van der Schueren B, Cassiman JJ, Van den Berghe H: Developmental changes in heparan sulfate expression: in situ detection with mAbs. J Cell Biol 1992, 119:961-975

51. Tsolis AC, Papandreou NC, Iconomidou VA, Hamodrakas SJ: A consensus method for the prediction of "aggregation-prone" peptides in globular proteins. PLoS One 2013, 8:e54175

52. Bergstrom J, Gustavsson A, Hellman U, Sletten K, Murphy CL, Weiss DT, Solomon A, Olofsson BO, Westermark P: Amyloid deposits in transthyretin-derived amyloidosis: cleaved transthyretin is associated with distinct amyloid morphology. J Pathol 2005, 206: 224-232

53. Okamoto K, Honda K, Doi K, Ishizu T, Katagiri D, Wada T, Tomita K, Ohtake T, Kaneko T, Kobayashi S, Nangaku M, Tokunaga K, Noiri E: Glypican-5 increases susceptibility to nephrotic damage in diabetic kidney. Am J Pathol 2015, 185:1889-1898 
54. Motamedi-Shad N, Monsellier E, Chiti F: Amyloid formation by the model protein muscle acylphosphatase is accelerated by heparin and heparan sulphate through a scaffolding-based mechanism. J Biochem 2009, 146:805-814

55. Marcoux J, Mangione PP, Porcari R, Degiacomi MT, Verona G, Taylor GW, Giorgetti S, Raimondi S, Sanglier-Cianferani S, Benesch JL, Cecconi C, Naqvi MM, Gillmore JD, Hawkins PN, Stoppini M, Robinson CV, Pepys MB, Bellotti V: A novel mechanoenzymatic cleavage mechanism underlies transthyretin amyloidogenesis. EMBO Mol Med 2015, 7:1337-1349

56. Horonchik L, Tzaban S, Ben-Zaken O, Yedidia Y, Rouvinski A, Papy-Garcia D, Barritault D, Vlodavsky I, Taraboulos A: Heparan sulfate is a cellular receptor for purified infectious prions. J Biol Chem 2005, 280:17062-17067

57. Hijazi N, Kariv-Inbal Z, Gasset M, Gabizon R: PrPSc incorporation to cells requires endogenous glycosaminoglycan expression. J Biol Chem 2005, 280:17057-17061

58. Shyng SL, Lehmann S, Moulder KL, Harris DA: Sulfated glycans stimulate endocytosis of the cellular isoform of the prion protein, PrPC, in cultured cells. J Biol Chem 1995, 270:30221-30229

59. Mikawa S, Mizuguchi C, Nishitsuji K, Baba T, Shigenaga A, Shimanouchi T, Sakashita N, Otaka A, Akaji K, Saito H: Heparin promotes fibril formation by the N-terminal fragment of amyloidogenic apolipoprotein A-I. FEBS Lett 2016, 590:3492-3500

60. Sekijima Y, Tokuda T, Kametani F, Tanaka K, Maruyama K, Ikeda S: Serum transthyretin monomer in patients with familial amyloid polyneuropathy. Amyloid 2001, 8:257-262

61. Noborn F, Ancsin JB, Ubhayasekera W, Kisilevsky R, Li JP: Heparan sulfate dissociates serum amyloid A (SAA) from acute-phase highdensity lipoprotein, promoting SAA aggregation. J Biol Chem 2012, 287:25669-25677

62. Nagamine S, Tamba M, Ishimine H, Araki K, Shiomi K, Okada T, Ohto T, Kunita S, Takahashi S, Wismans RG, van Kuppevelt TH, Masu M, Keino-Masu K: Organ-specific sulfation patterns of heparan sulfate generated by extracellular sulfatases Sulf1 and Sulf2 in mice. J Biol Chem 2012, 287:9579-9590

63. Jennette J, Heptinstall RH: Heptinstall's Pathology of the Kidney. ed 6. Philadelphia, PA, Lippincott Williams \& Wilkins, 2007

64. Lobato L, Beirao I, Silva M, Bravo F, Silvestre F, Guimaraes S, Sousa A, Noel LH, Sequeiros J: Familial ATTR amyloidosis: microalbuminuria as a predictor of symptomatic disease and clinical nephropathy. Nephrol Dial Transplant 2003, 18:532-538

65. Lobato L, Beirao I, Silva M, Fonseca I, Queiros J, Rocha G, Sarmento AM, Sousa A, Sequeiros J: End-stage renal disease and dialysis in hereditary amyloidosis TTR V30M: presentation, survival and prognostic factors. Amyloid 2004, 11:27-37

66. Haraldsson B, Nystrom J, Deen WM: Properties of the glomerular barrier and mechanisms of proteinuria. Physiol Rev 2008, 88:451-487

67. Vaamonde CPG, Pardo V: Dysproteinemias: multiple myeloma, amyloidosis and related disorders. Edited by Schrier R, Gottschalk C. In Diseases of the Kidney. ed 5. Boston, MA: Little, Brown, 1992. pp. 2189-2237

68. Filmus J, Selleck SB: Glypicans: proteoglycans with a surprise. J Clin Invest 2001, 108:497-501

69. Fujihara Y, Ikawa M: GPI-AP release in cellular, developmental, and reproductive biology. J Lipid Res 2016, 57:538-545
70. Floege J, Eng E, Lindner V, Alpers CE, Young BA, Reidy MA, Johnson RJ: Rat glomerular mesangial cells synthesize basic fibroblast growth factor: release, upregulated synthesis, and mitogenicity in mesangial proliferative glomerulonephritis. J Clin Invest 1992, 90: $2362-2369$

71. Takeuchi A, Yoshizawa N, Yamamoto M, Sawasaki Y, Oda T, Senoo A, Niwa H, Fuse Y: Basic fibroblast growth factor promotes proliferation of rat glomerular visceral epithelial cells in vitro. Am J Pathol 1992, 141:107-116

72. Mertens G, Van der Schueren B, van den Berghe H, David G: Heparan sulfate expression in polarized epithelial cells: the apical sorting of glypican (GPI-anchored proteoglycan) is inversely related to its heparan sulfate content. J Cell Biol 1996, 132:487-497

73. Williamson D, Selfe J, Gordon T, Lu YJ, Pritchard-Jones K, Murai K, Jones P, Workman P, Shipley J: Role for amplification and expression of glypican-5 in rhabdomyosarcoma. Cancer Res 2007, 67:57-65

74. Issandou M, Darbon JM: Basic fibroblast growth factor stimulates glomerular mesangial cell proliferation through a protein kinase Cindependent pathway. Growth Factors 1991, 5:255-264

75. Ballermann BJ: Regulation of bovine glomerular endothelial cell growth in vitro. Am J Physiol 1989, 256:C182-C189

76. Kriz W, Hähnel B, Rösener S, Elger M: Long-term treatment of rats with FGF-2 results in focal segmental glomerulosclerosis. Kidney Int $1995,48: 1435-1450$

77. Floege J, Kriz W, Schulze M, Susani M, Kerjaschki D, Mooney A, Couser WG, Koch KM: Basic fibroblast growth factor augments podocyte injury and induces glomerulosclerosis in rats with experimental membranous nephropathy. J Clin Invest 1995, 96: 2809-2819

78. Floege J, Eng E, Young BA, Alpers CE, Barrett TB, Bowen-Pope DF, Johnson RJ: Infusion of platelet-derived growth factor or basic fibroblast growth factor induces selective glomerular mesangial cell proliferation and matrix accumulation in rats. J Clin Invest 1993, 92:2952-2962

79. Kiyota T, Ingraham KL, Jacobsen MT, Xiong H, Ikezu T: FGF2 gene transfer restores hippocampal functions in mouse models of Alzheimer's disease and has therapeutic implications for neurocognitive disorders. Proc Natl Acad Sci U S A 2011, 108:E1339-E1348

80. Morimoto-Tomita M, Uchimura K, Werb Z, Hemmerich S, Rosen SD: Cloning and characterization of two extracellular heparindegrading endosulfatases in mice and humans. J Biol Chem 2002, 277:49175-49185

81. Ornitz DM, Marie PJ: FGF signaling pathways in endochondral and intramembranous bone development and human genetic disease. Genes Dev 2002, 16:1446-1465

82. Guimond S, Maccarana M, Olwin BB, Lindahl U, Rapraeger AC: Activating and inhibitory heparin sequences for FGF-2 (basic FGF): distinct requirements for FGF-1, FGF-2, and FGF-4. J Biol Chem 1993, 268:23906-23914

83. Schlessinger J, Plotnikov AN, Ibrahimi OA, Eliseenkova AV, Yeh BK, Yayon A, Linhardt RJ, Mohammadi M: Crystal structure of a ternary FGF-FGFR-heparin complex reveals a dual role for heparin in FGFR binding and dimerization. Mol Cell 2000, 6: $743-750$

84. Marco S, Skaper SD: Amyloid beta-peptide1-42 alters tight junction protein distribution and expression in brain microvessel endothelial cells. Neurosci Lett 2006, 401:219-224 